\title{
MERAJUT TANAMAN OBAT KELUARGA DALAM BINGKAI PENDIDIKAN EKOLOGI
}

\author{
Institut Agama Kristen Negeri Manado \\ heldy.rogahang@iakn-manado.ac.id \\ Diterima 20 Maret 2019 \\ Disetujui 29 April 2019
}

Heldy J. Rogahang, Nency Aprilia Heydemans

\begin{abstract}
This study aims to analyze the results of ecological education research on the use of family medicinal plants in the GMIM Kakaskasen Maranatha Church. Education ranging from children to old age in cultivating family medicinal plants that are believed to have great benefits. Family medicinal plants are useful for preserving nature, the greening movement, herbs and medicines for human health. The method used in this study is a qualitative method with participatory observation techniques, in-depth interviews with four members of the congregation and literature studies such as books, journals, theses, internet. The results of this study indicate that ecological education in cultivating family medicinal plants does not attract the attention of young people, but is of interest to elderly mothers and women to mothers. The impact of ecological education as a marker of human reconciliation with nature. Apart from oneself, church and culture play a role in educating and preserving nature.
\end{abstract}

Keywords: Education, Ecology, Family Medicinal Plants

\begin{abstract}
ABSTRAK
Penelitian ini bertujuan untuk menganalisis hasil penelitian pendidikan ekologi tentang pemanfaatan tanaman obat keluarga di Jemaat GMIM Kakaskasen Maranatha. Pendidikan di mulai dari anak sampai usia lanjut dalam membudidayakan tanaman obat keluarga yang diyakini memiliki manfaat yang besar. Tanaman obat keluarga bermanfaat untuk melestarikan alam, gerakan penghijauan, bumbu dapur dan obat untuk kesehatan manusia. Metode yang digunakan dalam penelitian ini ialah metode kualitatif dengan teknik observasi partisipatif, wawancara mendalam kepada empat anggota jemaat dan studi pustaka seperti buku, jurnal, skripsi, internet. Hasil penelitian ini menunjukkan pendidikan ekologi dalam membudidayakan tanaman obat keluarga kurang menarik perhatian anak muda, namun diminati para ibu lansia dan wanita kaum ibu. Dampak pendidikan ekologi sebagai penanda adanya rekonsiliasi manusia dengan alam. Selain dari diri sendiri, gereja dan budaya ikut berperan mendidik dan melestarikan alam.
\end{abstract}

Kata Kunci: Pendidikan, Ekologi, Tanaman Obat Keluarga

\section{PENDAHULUAN}

Pendidikan memegang peranan penting dalam merekonstruksi keyakinan, pemahaman dan perilaku manusia. Salah satu penyebab ketidakberdayaan masyarakat adalah tidak terjangkaunya sistem pendidikan persekolahan dan kurang berkembangnya kegiatan pendidikan luar sekolah yang ada di antara mereka. Oleh karena itu, menurut Anwar kehadiran pendidikan luar sekolah perlu berbasis sosial budaya (kontekstual) dan melihat 
potensi alam sekitar untuk memberdayakan masyarakat. ${ }^{1}$

Pendidikan merupakan sebuah proses pembebasan dalam mewujudkan gerakan sosial yang mandiri dan mempunyai sikap kritis. Pendidikan perlu disesuaikan dengan komunitas akar rumput, misalnya pendidikan kelompok perempuan pedesaan, pesisir dan pegunungan. ${ }^{2}$ Oleh sebab itu, pendidikan harus mampu mentransformasi perilaku ekologi manusia. ${ }^{3}$ Pendidikan ekologi mendorong terciptanya pengalaman praktis untuk mewujudkan keberlangsungan hidup dengan menjaga dan melestarikan lingkungan agar tetap bersih dan sehat. ${ }^{4}$ Pendidikan berbasis ekologi memberikan kontribusi terhadap pendidikan secara umum. ${ }^{5}$ Upaya pendidikan ekologi dapat dilakukan secara formal dan informal dengan menekankan kearifan lokal. Dengan demikian, pendidikan ekologi dapat mempengaruhi aspek ekonomi, lingkungan hidup, dan sosial.

Sejak manusia mengenal peradaban maka ia mulai meningkatkan kualitas

1 Anwar, Manajemen Pemberdayaan Perempuan, (Bandung: Alfabeta, 2007,), h. 81.

2 Iva Sasmita, "Pendidikan Alternatif Perempuan: Perlawanan terhadap Mainstream Pendidikan", Jurnal Perempuan 44, 2005, h. 7-19.

3 Witoelar, Rahmat, 'Kepemimpinan Lingkungan untuk Masa Depan Berkelanjutan' dalam Arif Budimanta, Environmental Leadership. (Jakarta: ICSD, 2005), h. v.

4 Ahmad, Maghfur, "Pendidikan Lingkungan Hidup dan Masa Depan Ekologi hidup. Di tahun 1760-1840 terjadi perkembangan revolusi industri dari Eropa sampai Amerika. Manusia mulai menciptakan teknologi tidak ramah lingkungan seperti mesin-mesin teknologi yang menggunakan bahan bakar fosil di bidang pertanian dan perkebunan. Dampak positif dari kemajuan ilmu pengetahuan dan teknologi dapat mempermudah manusia melakukan pekerjaan secara cepat dan efisien. Di sisi lain, dapat merusak lingkungan hidup dalam waktu singkat dan manusia menjadi objek dari kemajuan teknologi modern. ${ }^{6}$

Muncul revolusi industri kedua dengan mengubah gaya hidup manusia lebih konsumtif di abad 19. Penggunaan computer dan internet terus tak terbendung. Kemudian, muncul revolusi industri ketiga dengan memproduksi begitu banyak keinginan manusia yang mengakibatkan terjadi kerusakan lingkungan seperti pemanasan global dan perubahan iklim. Dalam perkembangan berikutnya muncul revolusi industri 4.0 yang berpengaruh pada tatanan pasar global dunia. ${ }^{7}$ Dewasa ini,

Manusia." Jurnal Edukasia Islamika, Vol. 8 ( 1) 2010: h. 57-58.

5 Regula Kyburz-Graber, "A SocioEcological Approach to Interdisciplinary Environmental Education in Senior High Schools," Environmental Education Research 3, Vol. 1 (1997): h. $17-28$.

6 Wardhana, Wisnu Arya, Dampak Pencemaran Lingkungan, (Yogyakarta: Andi, 2004), h. 24-25.

7 Kasali, Rhenald, Disruption, (Jakarta: Gramedia, 2017), h. 124. 
muncul pandemi covid-19 yang berdampak pada penurunan populasi udara dan gas rumah kaca. Akitivitas manusia dihentikan dengan bekerja, belajar dan beribadah dari rumah. Menurut para peneliti di New York kepada British Broadcasting Corporation $(B B C)$ bahwa hasil awal riset mereka menunjukkan karbon dioksida (CO2), terutama dari mobil dan pabrik telah berkurang hampir 50\% dibandingkan dengan tahun lalu. ${ }^{8}$ Itu berarti manusia mulai bersahabat dengan alam melalui gaya hidup baru. Ajakan di era new normal bukan dilakukan secara parsial melainkan dilakukan oleh semua elemen masyarakat termasuk gereja.

Menurut William Chang, krisis lingkungan hidup disebabkan oleh ulah manusia. Ternyata pengelolahan lingkungan hidup secara bertanggung jawab belum membudaya, manusia terus menguras isi perut bumi demi kepentingan hidupnya. Akibatnya, semakin memanas suhu bumi. Oleh karena itu menurutnya perlu ada kesadaran dari manusia untuk membentuk sistem pendidikan ekologi dalam bersikap dan bertindak secara bertanggung jawab atas alam. ${ }^{9}$

Tanaman obat keluarga (TOGA) merupakan tumbuh-tumbuhan alami yang

${ }^{8}$ Barak, Hariz. "Kadar Polusi Udara Dunia Menurun Selama Pandemi Corona COVID-19". Diakses dari https://www.liputan6.com/publication pada 08 Juni 2020. mudah ditemukan di sekitar tempat tinggal. TOGA sudah masuk dalam program aras sinode GMIM akan tetapi programnya belum menyentuh akar rumput aras jemaat. Kurangnya pemahaman pendidikan ekologi dalam mengelola dan memanfaatkan TOGA menjadi masalah yang sudah diketahui, namun belum hidup dalam hati dan tindakan. Gereja perlu membangun jejaring dengan pemerintah dan budaya Minahasa untuk mengalakkan pendidikan ekologi. Sebagai konsekuensi, gereja melakukan penyadaran ekologi bahwa TOGA bagian dari sahabat manusia. Pendidikan ekologi perlu dilakukan sejak dini.

\section{KAJIAN LITERATUR}

Kajian mengenai jemaat menarik untuk dikaji dalam pendekatan pendidikan ekologi dalam rajutan tanaman obat keluarga. Pendekatan ini menarik karena terdapat banyak perspektif dalam konteks pemahaman berbeda. Lumonang Zet melakukan penelitian tentang pendidikan ekologi dalam bingkai pendidikan agama kristen. Penelitian ini tertuju pada siswa di SMK Negeri 1 Siau Barat Selatan. Menurutnya, pendidikan

\footnotetext{
9 William Chang, Moral Lingkungan Hidup, (Yogyakarta: Kanisius, 2001), h. 29.
} 
ekologi itu penting guna membentuk pemahaman peserta didik untuk menjaga, melestarikan alam, dan mampu berpartisipatif aktif dalam kehidupan berkelanjutan. Pendidikan ekologi menjadi bekal bagi peserta didik agar terus mencintai dan bertanggung jawab atas alam yang menjadi bagian dari iman umat Kristiani. ${ }^{10}$

Kholis Nur dan Rofikatul Karimah $^{11}$ mengkaji aksi budaya teoekologi yang dihubungkan dengan kurikulum pendidikan. Penelitian ini dilakukan di Blitar tentang pengembangan budaya teo-ekologi dan pelaksanaan pendidikan ekologi di sekolah. Pengembangan kurikulum berdasarkan pada dinamika eksternal dan internal sekolah. Menurutnya, diperlukan adanya mata pelajaran muatan lokal pendidikan ekologi yang dapat diaplikasikan melalui dua model yakni materi lingkungan hidup berkaitan dengan mata pelajaran lain dan muatan lokal bernuansa ekologi.

Dari kajian literatur di atas, penulis menemukan bahwa kajian pendidikan ekologi merupakan sebuah kajian yang sesungguhnya bukan barang baru. Banyak telaah yang sudah dilakukan terhadap hal

10 Lumonang, Zet, "Pendidikan Ekologi dalam Perspektif Pendidikan Agama Kristen bagi Siswa di SMK Negeri 1 Siau Barat Selatan." Skripsi. Fakultas Pendidikan Agama Kristen IAKN Manado, 2018., h . 1. tersebut. Menjadi relatif baru, jika sebuah penjelajahan terhadap tanaman obat keluarga khususnya yang terkait dengan pendidikan ekologi sebagai sebuah proses pemberdayaan di jemaat menjadi dasar kajian ini. Sepanjang pengetahuan penulis, pembahasan mengenai merajut tanaman obat keluarga dalam bingkai pendidikan ekologi dengan menggunakan kacamata pemberdayaan jemaat masih merupakan sebuah petualangan intelektual yang langka. Tidak salah, jika hal tersebut bak "pohon yang ditanam di tepi sungai", mengeluarkan buah pada musimnya, daunnya tidak pernah layu, akarnya makin kokoh dan buahnya bisa dinikmati sebagai bagian dari matra abad.

\section{METODE PENELITIAN}

Penelitian ini menggunakan metode kualitatif dengan pendekatan deskriptif dengan memahami dan meneliti makna sekelompok manusia di masa sekarang. ${ }^{12}$ Penelitian ini berfokus pada jemaat yang melakukan aksi penanaman tanaman obat keluarga (TOGA) di rumah. Melalui penyadaran pendidikan ekologi, gaya hidup jemaat mengalami transformasi ramah lingkungan. Pemilihan informan dilakukan

11 Kholis, Nur Dan Rofikatul Karimah, "Aksi Budaya Teo-Ekologi Melalui Integrasi Kurikulum Pendidikan Lingkungan Hidup. Jurnal Pemikiran Islam, Vol. 17 ( 2) 2017 : h. 451-470.

12 Sugiyono, Memahami Penelitian Kualitatif, (Bandung: Alfabeta, 2007), h. 14. 
secara purposif sesuai dengan kebutuhan penelitian. $^{13}$

Karakter informan difokuskan pada pemuda, pria kaum bapa, wanita kaum ibu dan lanjut usia di Jemaat GMIM Kakaskasen Maranatha. Penelitian ini terdiri atas empat informan, yaitu: Christy Supit (CS, 24 tahun), Vecky Surentu (VS, 60 tahun), Nontje Assa (NA, 50 tahun) dan Juliana Moningka (JM, 70 tahun). Adapun manfaat dilakukan wawancara pada informan yakni untuk menggali informasi berkaitan tentang TOGA melalui pendidikan ekologi di jemaat. Metode ini menunjuk pada fenomena manusia menempatkan alam dan manusia sebagai agen transformasi. ${ }^{14}$ Selain itu, penelitian ini menggunakan studi pustaka berupa buku, jurnal dan artikel.

\section{KERANGKA TEORI}

\section{Perspektif Pendidikan}

Pemikiran Paulo Freire, tokoh revolusioner dalam bidang pendidikan dikenal dengan semangat perlawanan. Meskipun Freire tidak secara langsung

13 Cresswell, Jhon W, Research Design, (London: Sage Publication, 2015)

14 Rustandi, Arip. "Ruang Lingkup Geografi." Diakses dari https:/geografiarip.blogspot. com/2011/publication pada 08 Juni 2020. menyinggung anak perempuan, tetapi model pendidikan alternatif memberikan perspektif untuk menyentuh isu ketimpangan gender dalam bidang pendidikan. Ia memaparkan suatu model pendidikan yang menjamah langsung kaum miskin, termasuk di dalamnya kaum perempuan, kaum yang tertindas oleh struktur yang tidak adil. Pendidikan merupakan proses bagi pembebasan manusia. ${ }^{15}$ Jadi, pendidikan di sini tidak boleh memisahkan perempuan dan laki-laki dari dunia karena manusia berada dalam sejarah yang dibuatnya.

Menurut Mahatma Gandhi (18691984), pendidikan tidak hanya terdapat dalam dunia formal saja melainkan dalam bidang pendidikan informal (keterampilan) dan memungkinkan murid itu menghasilkan barang dari hasil pendidikan yang diperolehnya. Pendidikan kejuruan ini bertujuan untuk mengembangkan kemampuan, mental, fisik sehingga memberikan keuntungan ekonomi. Oleh karena itu, pentingnya upaya penyadaran dalam bidang pendidikan. Akhirnya, ia setuju bahwa setiap sekolah menjadi swasembada dengan keterlibatan negara India membeli hasil kerajinan tangan. Ia

15 Paulo, Freire, Pendidikan Sebagai Praktek Pembebasan, (Jakarta: Gramedia, 1984), h. 114-115. 
berpemahaman bahwa setiap orang (apakah laki-laki atau perempuan) bebas menempuh pendidikan. ${ }^{16}$ Dampak pendidikan dapat menerobos tembok subordinasi bagi anak pribumi (lebih khusus bagi anak perempuan). Corak perjuangan ini menjadi berwarna jika pendidikan terdiri atas pendidikan keluarga, pendidikan formal dan pendidikan informal yang memperjuangkan kesetaraan, hak dan pemberdayaan. Perjuangan ini perlu dilihat berdasarkan situasi dan kondisi wilayah tertentu.

\section{Tanaman Obat Keluarga}

Di zaman prasejarah manusia sudah memanfaatkan tanaman sebagai obat. Kemudian pada abad ke-16 didirikan kebun raya modern pertama di Pisa, Padova, Italia merupakan kebun tanaman obat yang digunakan oleh sekolah kedokteran masa itu. Hingga pada abad ke-21 ini, manusia terus mencoba menemukan obat untuk mengurangi dan menyembuhkan penyakit. ${ }^{17}$ Istilah TOGA lebih dikenal dengan nama apotek hidup. Dengan semakin meningkatnya kesadaran akan pola hidup sehat, pengobatan dengan menggunakan obat herbal sudah tidak lagi

\footnotetext{
${ }^{16}$ Mahatma Gandhi, All men are brothers: Life and Thoughts of Mahatma Gandhi as told in his own words, terj. Kustiniyati Mochtar, (Jakarta: Yayasan Obor, 2009), h. 186-195.

17 Astrid, Savitri, Tanaman Ajaib Basmi Penyakit dengan TOGA (Tanaman Obat Keluarga): Mengenal Ragam dan Khasiat TOGA, Meramu
}

dianggap kampungan atau ketinggalan zaman. Sebaliknya, menggunakan bahan alami sebanyak mungkin dalam kehidupan dapat menunjuk pada gaya hidup hijau dan tren go green.

Manusia mulai mengenai jenis TOGA dari akar, umbi, batang dan daun untuk mengobati berbagai penyakit. Di setiap perkembangan peradaban manusia, TOGA diidentifikasikan, dicatat dan diturunkan pada generasi selanjutnya. Hal ini membuktikan bahwa TOGA tidak terpisahkan dari sejarah umat manusia di dunia. ${ }^{18}$ Dalam satu decade terakhir, pengobatan Barat mencoba menggunakan TOGA dan menyatukan penggunaannya ke dalam sistem medis modern. Alasannya: Pertama, murah dengan harga terjangkau, Kedua, nilai obat, minim efek samping bagi manusia karena bersifat alami. Karena itu, dengan memahami manfaat dan khasiat jenis tanaman tertentu, tanaman obat menjadi pilihan keluarga dalam memilih obat alami yang aman. Di Indonesia, TOGA tumbuh subur dengan beraneka ragam jenis. Dimanfaatkan dalam pembuatan jamu dan obat herbal. Hal yang sama juga terlihat dari pemanfaatan TOGA bagi jemaat GMIM Kakaskasen Maranatha.

Jamu Tradisonal atau Herbal dengan TOGA, (Depok: Bibit Publisher, 2006), h. 1-3.

${ }^{18}$ Suparni, Ibunda dan Ari Wulandari, Seri Herbal Nusantara: Herbal Papua - Khasiat dan Ramuan Asli dari Papua Penumpas Segala Penyakit Mematikan, (Yogyakarta: Rapha Publishing, 2006), h. 7 . 
Data jemaat tahun 2020 berjumlah 1.745 jiwa dengan 507 kepala keluarga (KK) yang terdiri dari usia lanjut 223 jiwa, pria kaum bapa 511 jiwa, wanita kaum ibu 529 jiwa, pemuda 228 jiwa, remaja 189 jiwa dan anak sekolah minggu 282 jiwa. Pada data ini, jemaat menjadi bagian dari pendidikan ekologi untuk memanfaatkan tanaman obat keluarga dengan baik dan benar. Ini tertuang dalam program jemaat dan aksi bersama dalam berpikir global dan bertindak lokal melalui ibadah, khotbah, dan mempraktekan gaya hidup ramah lingkungan sebagai percontohan project TOGA di samping gedung gereja.

\section{TEMUAN DAN ANALISIS}

Bagian ini akan memaparkan hasil penelitian dan analisis lapangan tentang pendidikan ekologi yang terdapat di jemaat GMIM Kakaskasen Maranatha dalam aksi merajut tanaman obat keluarga.

\section{Merajut Tanaman Obat} Keluarga dalam Bingkai Pendidikan

\section{Ekologi Melalui Narasi Empat Pemuda}

"Saya menanamkan sikap peduli dengan tanaman obat keluarga. Oleh sebab itu, berdasarkan ajaran Kristen tentang kasih, maka saya mulai menanamkan pendidikan ekologi yang diajarkan gereja dalam khotbah dengan bercocok tanam jenis tanaman obat keluarga di samping rumah seperti jahe, kunyit, lengkuas, serei, kucae, daun tebal, bawang, dan daun patah tulang. Jadi, di pekarangan rumah bukan hanya aneka bunga yang ada tetapi ada terdapat beraneka jenis tumbuhan obat. Ini mulai dijabarkan melalui program jemaat dalam lomba antar kolom tumbuhtumbuhan tanaman obat keluarga, dalam renungan khotbah pendeta, terlebih inisiatif diri sendiri untuk menanam tumbuhan obat diri. Aksi ini mendapat dukungan oleh semua anggota jemaat terutama usia lanjut, dan pemerintah yang tiga tahun lalu menyelenggarakan lomba tanaman obat antar lingkungan keluarahan Kakaskasen yang disediakan setiap keluarga di depan rumahnya." - JM (70 tahun)

Informan PT menyampaikan bahwa aksi peduli ini bertumbuh dari kesadaran diri sendiri untuk menanam tanaman obat keluarga. Ia merupakan salah satu pengurus Lansia di kolom 20 jemaat GMIM Kakaskasen Maranatha periode 2018-2022. Pendidikan ekologi di jemaat telah disampaikan melalui khotbah renungan untuk peduli dengan alam yang mulai rusak, program kerja lomba hasil expo pertanian antar kolom yang di dalamnya ada persyaratan apotek hidup. Melalui program kerja ini sebagian besar lansia terpanggil untuk membudidayakan TOGA dengan mempersiapkan tanah, dan lahan pekarangan untuk ditanam. Pendidikan ekologi PT wariskan pada anak mereka melalui ajakan ikut bertanam dengan penuh kasih tanpa beban.

Dari pemaparan di atas bahwa menjadi salah satu pengurus lansia gereja perlu memiliki jiwa solidaritas, kasih dan 
teladan menghadapi krisis alam. Menanam berarti ikut andil dalam kelestarian alam melalui aksi go green. Peran gereja saat ini dilakukan untuk kehidupan ekologi yang lebih baik di masa depan. ${ }^{19}$ Tidak lupa melibatkan stakeholders dalam aksi penghijauan dan penanaman TOGA. Berpikir global, bertindak lokal itulah yang telah dilakukannya.

Sementara itu NA mengatakan penanaman TOGA telah didukung oleh pemerintah dengan dilombakan pondokpondok yang berisi tanaman TOGA dalam rangka memperingati Hari Ulang Tahun Republik Indonesia. Begitu juga mendapat dukungan gereja melalui wanita kaum ibu mengajak semua ibu bukan hanya menanam bunga saja, melainkan menanam TOGA yang bermanfaat sebagai obat dari berbagai jenis penyakit dan bumbu dapur atau bumbu masak. Jadi, kebutuhan setiap hari tidak perlu lagi membeli di pasar dan atau di sepeda motor bumbu dapur. Ini juga bermanfaat meminimalisir pengeluaran ekonomi keluarga.

"Adanya seruan dari pemerintah kota Tomohon, sudah dilakukan tiga tahun yang lalu yang bermanfaat untuk mengiatkan warga bercocok tanam dalam pembudidayaan TOGA sebagai obat dari berbagai penyakit. Dalam kegiatan wanita kaum ibu seperti khotbah ibadah, pengajaran sudah disampaikan dan dingatkan untuk

19 Kerap, Sonny, Etika Lingkungan, (Jakarta: Buku Kompas, 2002), h. 144. menanam TOGA sebagai bagian dari menjalin hubungan yang baik antara manusia dan alam. Cikal bakal aksi ini merupakan warisan pendidikan orang tua saya dan telah menjadi hobi. Selain itu, dapat meminimalisir pengeluaran ekonomi keluarga dengan tidak lagi membeli bumbu dapur." - NA (50 tahun)

Menurut NA, bahwa pendidikan ekologi telah menjadi perhatian serius dari gereja dalam kegiatan peribadatan. Ini menjadi bukti bahwa gereja dan pemerintah ikut andil dalam pelestarian TOGA, pelestarian lingkungan. Terkait melalui program yang disampaikan, NA memiliki komitmen untuk membudidayakan TOGA sebagai gaya hidup, dimulai dari pendidikan keluarga dalam hal ini warisan orangtuanya untuk bercocok tanam kemudian tidak lepas sebagai hobi yang memberikan dampak positif bagi keluarga, jemaat dan masyarakat. Oleh sebab itu, kesadaran dari diri sendiri bahwa TOGA dapat dimanfaatkan sebagai obat dan meminimalisir pengeluaran ekomoni keluarga dengan adanya bumbu dapur yang sudah tersedia di pekarangan rumah.

Sementara itu, VS seorang Pria Kaum Bapa (PKB) yang merupakan salah satu pelayanan khusus di Jemaat GMIM Kakaskasen Maranatha mengaku bahwa pendidikan ekologi telah ditunjukkan 
dalam renungan, rapat sidi jemaat yang dibicarakan dalam program lingkungan hidup PKB kolom. Ini bertujuan agar supaya menjadi potensi di jemaat untuk dipamerkan dalam expo HUT jemaat. Aksi ini diterima antusias oleh semua jemaat dalam kegiatan lomba expo yang sementara berlangsung. Mengingat kota Tomohon bukan hanya disebut kota bunga memberi nilai estetika alam, melainkan kota TOGA yang tumbuh subur di tengah dingin, sejuknya alam.

"Setiap hari, kalau tidak hujan saya menanam TOGA, bunga dan membersihkan pekarangan rumah bersama istri. Akan tetapi, sebagai PKB seringkali muncul budaya malu kalau orang lain lihat saya menanam. Mengingat, kegiatan menanam jarang dilakukan oleh kaum laki-laki. Kegiatan menanam TOGA telah saya lakukan bersama istri meskipun itu seringkali hanya formalitas saya dan untuk menggerakan tubuh agar lebih segar beraktivitas. Kemudian, aksi menanam berdampak positif bagi gereja dengan memberikan edukasi pendidikan maka gereja ikut andil dalam gaya hidup hijau. Budaya Minahasa tidak lepas dari kegiatan para leluhur dengan bercocok tanam." - VS (60 tahun)

VS mengutarakan bahwa seringkali muncul rasa malu untuk menanam dari segi kaum laki-laki. Sebagai contoh kalau ia bersama istri sementara menanam TOGA dan bunga dilihat oleh orang lain. Ini masih dibingkai dengan rasa malu, gengsi dan kegiatan formalitas untuk menggerakan tubuh. VS mengatakan bahwa gereja ikut andil dalam memberi edukasi pendidikan ekologi. Meskipun sudah disosialisasikan namun belum semua PKB peka terhadap ekologi termasuk merawat, menjaga dan melestarikannya. Sebagai seorang pelayan khusus ia menunjukkan sikap menghargai alam yang didapatnya dari edukasi gereja. Ternyata, budaya Minahasa sudah mengajarkan kearifan lokal untuk bercocok tanam sebagai bagian dari tugas panggilan Tuhan bagi manusia.

Kemudian CS menyampaikan sebagai seorang pemudi gereja masih muncul dalam dirinya untuk belum terbiasa menanam, malas, rasa gengsi karena bercocok tanam dilakukan oleh orang tuanya. Gengsi ini muncul karena ada anggapan bahwa anak muda sekarang bukan bekerja di kebun, di pekarangan rumah untuk bercocok tanam melainkan kerja diperkantoran. Menurutnya tingkat pendidikan yang tinggi, tidak cocok untuk kerja di kebun. Sebagaimana wawancara yang dikutip di bawah ini:

"Saya seringkali tidak membantu orang tua di kebun atau dipekarangan rumah, ini disebabkan ada rasa malu, gengsi jika dilihat teman sebaya. Pendidikan yang tinggi, kurang cocok bekerja di kebun atau pekarangan rumah. Namun, dalam kegiatan katekisasi calon anggota sidi jemaat pernah menyampaikan materi pelestarian 
ekologi dengan tugas menanam bunga dan TOGA." - CS (24 tahun)

Sementara itu, CS mengatakan dalam katekisasi calon anggota sidi jemaat sudah pernah menyampaikan materi pelestarian lingkungan dengan tugas mandiri menanam bunga dan TOGA. Aplikasi penanaman TOGA dibawa ke gedung gereja untuk dihias sebagai estetika dan pengenalan akan manfaatnya. CS mulai berdamai dengan diri sendiri untuk menghadapi tantangan dari diri sendiri dengan menanamkan pendidikan ekologi yang ramah lingkungan tanpa membandingkan tingkat pendidikan yang ditempuh. Kemudian, tantangan keluar dari ejekan teman yang tidak mendidik.

Pendidikan ekologi yang disampaikan gereja dan pemerintah perlu dilakukan sejak dini dengan sikap ramah lingkungan. Sikap ini dimulai dari diri sendiri, keluarga, gereja dan masyarakat. Kearifan lokal tidak bertitik tolak pada konsumsi dan produksi yang banyak melainkan tanggapan Naess" "simple in means, but rich in ends" itu berarti bukan having more melainkan being more. Dalam perspektif keberlanjutan ekologi perlu pertimbangan konteks kontribusi manusia bagi terciptanya keseimbangan ekologi global. Oleh sebab itu, JM, NA, VS dan CS

${ }^{20}$ Naess, Arne., Ecology, Community and Life-style, (Cambridge: Cambridge Univ. Press, 1993), h. 88. sedang berupa menanamkan pendidikan ekologi melalui TOGA pada skala lokal berdampak pada lingkungan hidup secara global. Jika menilik apa yang disampaikan E. F. Schumacher dalam arti serba kecil, sederhana melalui upaya perubahan pola pikir manusia untuk bersikap dan bertingkah laku terhadap pemanfaatan. Dengan demikian, gereja perlu berpikir secara global dan bertindak secara lokal (think global, act local).

\section{KESIMPULAN}

Berdasarkan penelitian tentang merajut tanaman obat keluarga dalam bingkai pendidikan ekologi dapat dikatakan belum semua anggota jemaat melakukan aksi penanaman tanaman obat keluarga. Padahal pendidikan ekologi telah dilakukan oleh gereja dan pemerintah. Oleh karena itu perlu adanya kesadaran dari diri sendiri untuk membangun minat dan mengedukasi keluarga. Dampak pendidikan ekologi sebagai penanda adanya rekonsiliasi manusia dengan alam. Implikasi pendidikan ekologi dalam aksi bersama menyentuh aspek ekonomi, sosial dan budaya.

\section{DAFTAR PUSTAKA}

Ahmad, Maghfur, "Pendidikan Lingkungan Hidup dan Masa Depan Ekologi 
Manusia." Jurnal Edukasia Islamika. Vol. 8 ( 1), 2010.

Anwar, Manajemen Pemberdayaan

Perempuan, Bandung: Alfabeta, 2007.

Astrid, Savitri, Tanaman Ajaib Basmi Penyakit dengan TOGA (Tanaman Obat Keluarga): Mengenal Ragam dan Khasiat TOGA, Meramu Jamu Tradisonal atau Herbal dengan TOGA, Depok: Bibit Publisher, 2006.

Barak, Hariz. "Kadar Polusi Udara Dunia Menurun Selama Pandemi Corona COVID-19". Diakses dari https://www.liputan6.com/publicati on pada 08 Juni 2020.

Cresswell, Jhon W, Research Design, London: Sage Publication, 2015.

Iva Sasmita, "Pendidikan Alternatif Perempuan: Perlawanan terhadap Mainstream Pendidikan", Jurnal Perempuan 44, 2005.

Kasali, Rhenald, Disruption, Jakarta: Gramedia, 2017.

Kerap, Sonny, Etika Lingkungan, Jakarta:

Buku Kompas, 2002.

Kholis, Nur Dan Rofikatul Karimah, "Aksi Budaya Teo-Ekologi Melalui Integrasi Kurikulum Pendidikan Lingkungan Hidup. Jurnal Pemikiran Islam. Vol. 17 (2), 2017.

Lumonang, Zet, "Pendidikan Ekologi dalam Perspektif Pendidikan Agama Kristen bagi Siswa di SMK Negeri 1 Siau Barat Selatan." Skripsi. Fakultas Pendidikan Agama Kristen IAKN Manado, 2018.

Mahatma Gandhi, All men are brothers: Life and Thoughts of Mahatma Gandhi as told in his own words, terj. Kustiniyati Mochtar, Jakarta: Yayasan Obor, 2009.

Naess, Arne, Ecology, Community and Life-style, Cambridge: Cambridge Univ. Press, 1993.

Paulo, Freire, Pendidikan Sebagai Praktek

Pembebasan, Jakarta: Gramedia, 1984.

Regula Kyburz-Graber, "A SocioEcological Approach to Interdisciplinary Environmental Education in Senior High Schools," Environmental Education Research 3, Vol. 1, 1997.

Rustandi, Arip, "Ruang Lingkup Geografi." Diakses dari https://geografi-arip.blogspot. com/2011/publication pada 08 Juni 2020 .

Sugiyono, Memahami Penelitian Kualitatif, Bandung: Alfabeta, 2007.

Suparni, Ibunda dan Ari Wulandari, Seri Herbal Nusantara: Herbal PapuaKhasiat dan Ramuan Asli dari Papua Penumpas Segala Penyakit Mematikan. Yogyakarta: Rapha Publishing, 2006,

Wardhana, Wisnu Arya, Dampak Pencemaran Lingkungan, Yogyakarta: Andi, 2004.

William, Chang, Moral Lingkungan Hidup, Yogyakarta: Kanisius, 2001.

Witoelar, Rahmat, 'Kepemimpinan Lingkungan untuk Masa Depan Berkelanjutan' dalam Arif Budimanta, Environmental Leadership, Jakarta: ICSD, 2005 